\title{
LEFT, RIGHT, AND THE ITALIAN VOTER
}

\author{
SAMUEL H. BARNES \\ University of Michigan
}

\section{T}

he great payoff for empirical research is an excellent fit between theory and data. The pleasure of the accomplishment is intensified by its rarity. Social science has been much better at criticism than validation, at revealing that what we think we know is in fact not so than in constructing useful models of behavior. It is even more unusual for research to demonstrate the empirical foundation of conventional wisdom. Hence one of the rarest experiences of all is to have theory and data confirm the essential verisimilitude of political folklore. And yet to report such esoteric findings is the pleasant task of the present paper.

Spatial models of party competition are among those that have not fared well when juxtaposed to data. Nevertheless, it is commonplace for scholars, politicians, journalists, and others to analyze politics in spatial terms. The assumption that parties, policies, and politicians can be located at a particular point in a space that extends from left to right has long been current in the idiom of politics. It is not at all strange that the terms

AUTHOR'S NOTE: The data collection was financed by a Ford Foundation institutional grant for international programs to the University of Michigan, by a grant from the Horace H. Rackham School of Graduate Studies of the University of Michigan, and by the United States Commission for Cultural Exchange with Italy, 
left and right should be especially relevant in Italy, for Italian parties, policies, politicians, and voters seem to fit neatly on a single left-right dimension. Multidimensionality, which often complicates spatial models, is not a problem. The socioeconomic, religious, and foreign policy dimensions of Italian politics turn out to be mutually reinforcing; they are mere segments of a basic continuum. At least according to the conventional wisdom. Before subjecting this contention to closer scrutiny a discussion of the background of the argument is needed.

\section{SPATIAL MODELS AND ITALIAN POLITICS}

In the search for elegance and parsimony in models of political behavior, students of politics have increasingly turned to the other social sciences that have pioneered in the search. One such model that has demonstrated great promise as an aid to abstract understanding of underlying political processes is derived from the analysis of optimum location of economic enterprises. Deriving from Harold Hotelling (1929: 41-57) and refined by Arthur Smithies (1941: 423-429), it has been applied to mass and elite democratic political behavior by Anthony Downs (1957: esp. ch. 8: 114-141; see also Laponce, 1970; Sartori, 1965).

The model demonstrated that the optimum location of an enterprise in relation to markets and to competitors would place competing firms near one another. The familiar analogy is that Woolworth and Kresge are near one another rather than at opposite ends of Main Street. In an inelastic market, each would recruit customers from its hinterland; there would be no likelihood of anyone passing by one store to shop at one further away, for location would ensure lower costs for customers nearer in space.

It is the merit of Downs (1957) that he has worked out the implications of this for party competition. Central to Downs' argument is the assumption that political parties seek office by adopting policies that will attract a maximum number of voters. These voters are strung out along a continuum that reaches from left to right. For Downs the relevant dimension is the extent of governmental intervention in the economy. The distribution of voters on that continuum reflects their attitudes toward

which awarded the author a Fulbright visiting lectureship at the University of Rome during 1967-1968. The analysis was made possible by the Ford Foundationsponsored Latin Political Culture project of the Center for Political Studies of the Institute for Social Research of the University of Michigan. I am especially grateful to Frank Casale and Peter Joftis for their assistance. 
that dimension and dictates the strategies that parties employ to seek votes. Logically it also determines the number of parties that exist in the system. The common bell-shaped curve distribution of voters, for example, encourages a two-party system, with the policies of the two converging and even overlapping in order to attract the voters in the center. A bimodal system, on the other hand, suggests a different type of two-party system, one that is highly polarized and with few shared policy preferences. A bimodal or multimodal system might logically lead to a multiparty system. As the curve becomes flatter fewer people would be occupying an equivalent segment and the difficulty of reconciling the policy needs of the different segments would increase. This would encourage the proliferation of parties to appeal to particular segments of the distribution. Rather than the converging policy preferences in a two-party system, multiparty systems encourage sharp differentiation of policies between parties adjacent on the continuum.

Additional discussion of the general patterns of relationships between party systems and the distribution of opinions would carry us far afield from our present subject, which is the particular pattern in Italy rather than a critique of spatial models in general. However, several important theoretical questions should be noted. One concerns the nature of the space of the left-right continuum. What does it contain? Is it viewed similarly by elites and mass? Do different political groups agree on its composition? Insofar as they relate to spatial models in general these questions fall outside the province of the present paper. Yet it is necessary to specify what the space refers to in the present paper. Downs labeled the space "ideology," which is not the same thing as to define it. His emphasis was on a single dimension, that of the degree of governmental intervention in the economy. He seems to use this example as a shorthand for sets of policy preferences and political orientations consisting of elements that somehow hang together. The interesting question of why they hang together is not dealt with; despite its obvious importance, this question will also be left unresolved in this paper. The sources of ideological constraint and its dispersal throughout large populations is too large a subject to discuss briefly. In this paper, consequently, we will deal with the left-right continuum as it was operationalized in the study-that is, as a scale on which respondents were asked to place themselves and the parties of the Italian system. Unlike Downs' reference to the desired degree of government intervention in the economy, our left-right dimension is open in meaning, with only the respondent (if anyone) knowing precisely what dimension was intended. 
Even if it is possible not to confront directly the question of the content of the space-and we believe that it is legitimate to avoid this particular confrontation-it is not so easy to ignore several problems of the model that derive from assumptions concerning the nature of the space. These have been analyzed by Donald Stokes as the axioms of unidimensionality, fixed structure, ordered dimensions, and common reference (Campbell et al., 1966: esp. 165-176). He notes that the unreality of these axioms as applied to actual polities greatly weakens the appeal of spatial models. It is our thesis that the axioms do not greatly distort the reality of Italian politics. A short discussion will clarify the meaning and limitations of the thesis.

The axiom of unidimensionality posits that a single dimension dominates the politics of the polity. For Downs this was the degree of governmental intervention in the economy. As Stokes has pointed out, other dimensions quite often have been widely viewed as more important, and in all polities there is some degree of disagreement as to what constitutes the crucial issues. Religious cleavages have often been as important as economic ones, for example, and there is no logical or empirical reason for assuming that the distribution of opinions on one of these dimensions parallels that on the other. As dimensions are added, the number of possible combinations of opinions increases rapidly, and there could be a party to represent each possible combination of opinions. In practice, not every combination is equally likely to require recognition, but extant systems illustrate the very large number of parties that can be generated by a multidimensional politics.

The Italian polity is certainly a case in point. Italians are divided along the socioeconomic, religious, and foreign policy dimensions plus numerous less salient ones. However, the multiple cleavages do not cancel out a strong overall relationship between left-right position and party identification. One reason is that the large parties are essentially consistent on the three major dimensions. That is, the Communists tend to be redistributive, anticlerical, and anti-American, while the Christian Democrats are less redistributive, more clerical, and pro-American. Another reason is that those Italian parties that do not fit so neatly into this spatial model have few supporters compared to the mass parties that do conform to its expectations. Finally, the determining dimensions for voters may in reality be only a subset of those current in political debate. The inquiry into why the existence of multiple dimensions is compatible with a single left-right continuum will be taken up again in the paper. 
The axiom of fixed structure suggests that the definition of the space remains unchanged. Political reality, however, certainly is not fixed; issues change, parties surge and decline, political fads come and go. This paper cannot deal with the question of changes in Italian politics. The data derive from a single study conducted at a particular moment in time. Although our study does contain information about prior voting preferences, change lies outside the scope of the paper. But when an analysis of voting change in Italy is eventually concluded it will probably demonstrate considerable stability in individual voting habits in the twenty years preceding this election in 1968. Preliminary analysis shows that at least $80 \%$ of the 1968 electorate claimed to have always voted for the same party. Considering only the electoral returns, which may, of course, be misleading, losses and gains of each party are quite small from election to election. Earlier elections, especially that of 1948, were conducted on the issue of God against communism. Recent elections have been more prosaic affairs dealing as much with policy questions as with ideology, at least as compared with 1948. It is our hunch that the political attitudes of the individual Italian voter have changed very slightly and only quite slowly in the past few years. This is only an informed aside; it is certainly not a prediction of future patterns.

The third axiom, that of ordered dimensions, posits that the parties can be ranked according to their stand on issues. Stokes, following Kurt Lewin, distinguishes between "valence issues," which "merely involve the linking of the parties with some condition that is positively or negatively valued by the electorate" (Campbell et al., 1966: 173), and position issues. Thus valence issues would not fit the spatial scheme, as all of the parties might in fact take the same position. Honesty in government, for example, is not likely to be the monopoly of a single party platform; it might, however, be the determining factor in an individual's vote because he feels that one party would in fact act with more integrity than another. In the Italian case we uncovered several valence issues such as economic development of Italy, improvement of schools, and governmental stability. Analysis indicates that attitudes toward these issues are not as closely linked with partisan identification as are attitudes toward position issues on socioeconomic, religious, and foreign policy questions. The evidence seems clear that in the Italian case in 1968 position rather than valence issues were determining. Again, we must enter the caveat that we are discussing a single election.

The final axiom is that of common reference, the possession of agreement between elites and mass as to the alternatives of governmental 
action. More than the other three, this is a question of degree. It is obvious that elite and mass do not view the system in exactly the same way anywhere. It seems equally clear that there is substantial congruence between the policy preferences of mass publics and elites in Italy, though it may be due as much to organizational and socialization variables as to ideology. The differences between Communist elites and voters, for example, are considerable on a number of dimensions, and the same can be said of the Christian Democrats. It is less certain that any profound political consequences flow from these differences. It is doubtful that complete agreement would make much difference for the political system, though it might alter the mobilization styles of elites if it were somehow to be achieved. We are, however, concerned with the existence of agreement and not its causes and consequences. A further discussion of the ramifications of the problem of common reference is reserved for a later point in the paper.

As this is a single study at a particular time, there is little that we can say about the problem of fixed structure or change in the definition of the space. Consequently, we will concentrate on the problems of unidimensionality, ordered dimensions, and common elite-mass references. Before turning to these questions the overall results will be presented.

\section{THE ITALIAN ELECTORATE: LEFT AND RIGHT}

It is the perceptions of mass publics rather than of elites that complicate most attempts to construct left-right models of party competition. Although mass publics may not seem to be clearly aware of left-right dimensions, it is seldom difficult for knowledgeable observers to detect meaningful gradations among parties along numerous dimensions; and it is usually possible to reduce these to a summary left-right dimension. Hence we will begin with the more difficult case-the mass public.

It is not difficult for voters to think in left-right terms in the homeland of the world's largest nonruling Communist party-the symbol par excellence of the left-as well as the cradle of three potent symbols of the twentieth century right-the Catholic church, the joint stock company, and fascism. Italy's history seems to encourage left-right thinking. Patterns of social stratification and the resulting elitism have exacerbated cleavages originating in both agricultural and industrial societies, and their historical legacies are a body politic sharply divided by ideology and social class. The early dominance of the country by the Liberals, the rise of Marxian 
socialism and its subsequent fragmentation, the mobilization of Catholics into a mass party that in part transcends class dimensions, and the survival of Fascist sympathies gave rise to parties holding the present loyalties of more than $95 \%$ of the voters. The result is three voting blocs easily identifiable by most Italian voters-the left, right, and Catholic, the last being in fact, as we will see, a center bloc.

The left consists of the Communist party (PCI, using its Italian initials); a splinter Socialist party that is close to the PCI, the Socialist party of Proletarian Unity (PSIUP); at the time of the research the unified socialist party PSI-PSDI, which has since divided again into the Italian Socialist party (PSI) and the Unitary Socialist party (PSU); and the small Republican party (PRI), which carried on an older anticlerical but non-Marxian leftist tradition. The Christian Democratic party (DC) occupies the center of the spectrum. The right consists of the Liberal party (PLI), the Monarchists (MON), and Neofascists (MSI). National samples consistently underrepresent the Communist vote; though less seriously than in most studies, the present analysis also suffers from this problem. Table 1 gives the percentage of the vote received by each party in 1968 and the percentage of respondents who identified with the party. ${ }^{1}$ The DC and "other" are overrepresented, but the missing PCI identifiers constitute the most serious problem. Careful evaluation of the nonidentifiers demonstrates that they do not mask more than slightly more than the normal portion of these missing PCI identifiers. There is no evidence that the distortion that inevitably results from the low portion of PCI

\section{TABLE 1}

\section{PARTY VOTE AND SAMPLE PORTION}

\begin{tabular}{lcc}
\hline Party & $\begin{array}{c}\text { Vote Percentage 1968 } \\
\text { Election for Chamber } \\
\text { of Deputies }\end{array}$ & $\begin{array}{c}\text { Sample Percentage } \\
1968 \text { CISER Sample }\end{array}$ \\
\hline PCI & 26.9 & 11.1 \\
PSIUP & 4.4 & 2.0 \\
PSI.PSDI & 14.5 & 13.0 \\
PRI & 2.0 & 1.2 \\
DC & 39.1 & 42.0 \\
PLI & 5.8 & 2.2 \\
MON & 1.3 & .6 \\
MSI & 4.5 & 1.9 \\
Other & 1.5 & 5.5 \\
Nonidentifiers & - & 20.5 \\
\hline
\end{tabular}

Source of electoral results: Derek $W$. Urwin, ed., Elections in Western Nations, 1945-1968. Glasgow: Strathclyde SRC, n.d. (1969). 


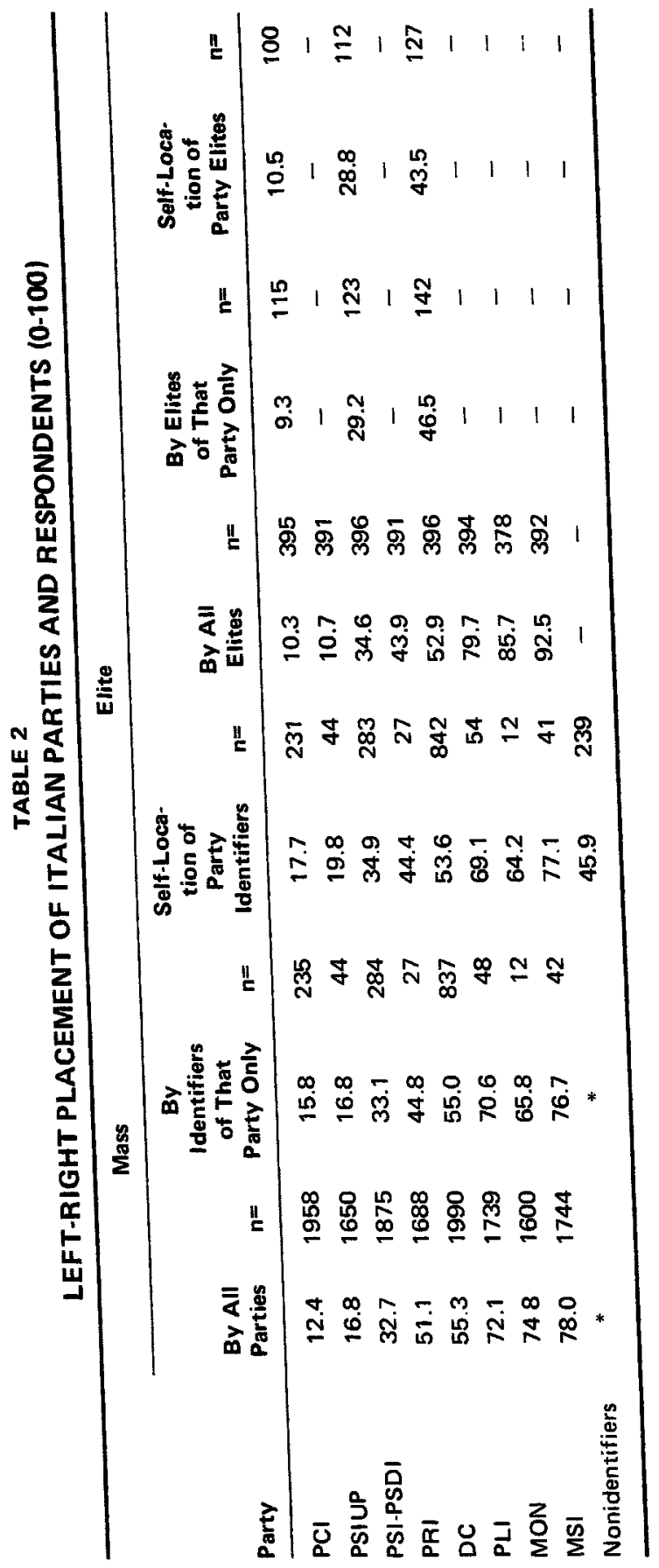


identifiers affects our overall findings, though it cannot be demonstrated that it does not.

National Italian political mores and the professional ethics of the interviewers precluded asking respondents how they voted in the previous election. Instead, respondents were asked: "To which party do you habitually feel closest?" plus questions dealing with consistency of voting, past voting behavior, closeness to party, and so on. As almost $80 \%$ claimed to have always voted for the same party, the fit between party identification and vote must be very close; but, given the uncertainties associated with recalled behavior, it should not be assumed.

The elites are 396 municipal councilors from a national sample of communes. Interviews were obtained with two Communist, two Socialist and two Christian Democratic councilors in each commune.

There would be virtually no disagreement among observers of Italian politics on the ranking of parties in Table 1; and, as we shall see, the mass and elites concur. In order to tap perceptions of the parties on the left-right continuum we asked respondents to place parties on a scale from the extreme left to the extreme right (that is, 0 to 100) that they had previously been able to identify. We also asked them to place themselves on the scale. Of the total voter sample, $76 \%$ were able to place themselves on the left-right continuum; the portion ranged from a maximum of $97 \%$ for the PLI identifiers to a low of $79 \%$ for the DC. Only $47 \%$ of the nonidentifiers could locate themselves on the scale. There are many confirmations of the fit between left-right placement and party identification. The ranking of the parties is similar to their placement by expert opinion, though it has been achieved by respondents of a country with a low level of formal education at the mass level and little claimed interest in politics. The overall elite ranking is similar to the overall mass ranking, though the numbers assigned the parties differ somewhat, especially on the right. This is in part due to the weight of the Socialists and Communists in the elite ranking, and to the absence of right-wing councilors in the elite sample.

The overall relationship between left-right self-placement and party identification at the mass level is very strong. The product moment correlation is .65 , tau beta is .63 and gamma .77. Examination of the distribution of the mass electorate will help to redefine our understanding of several aspects of the Italian system. Table 2 shows the overall distribution of left-right self-placement and the distribution of the individual parties. 

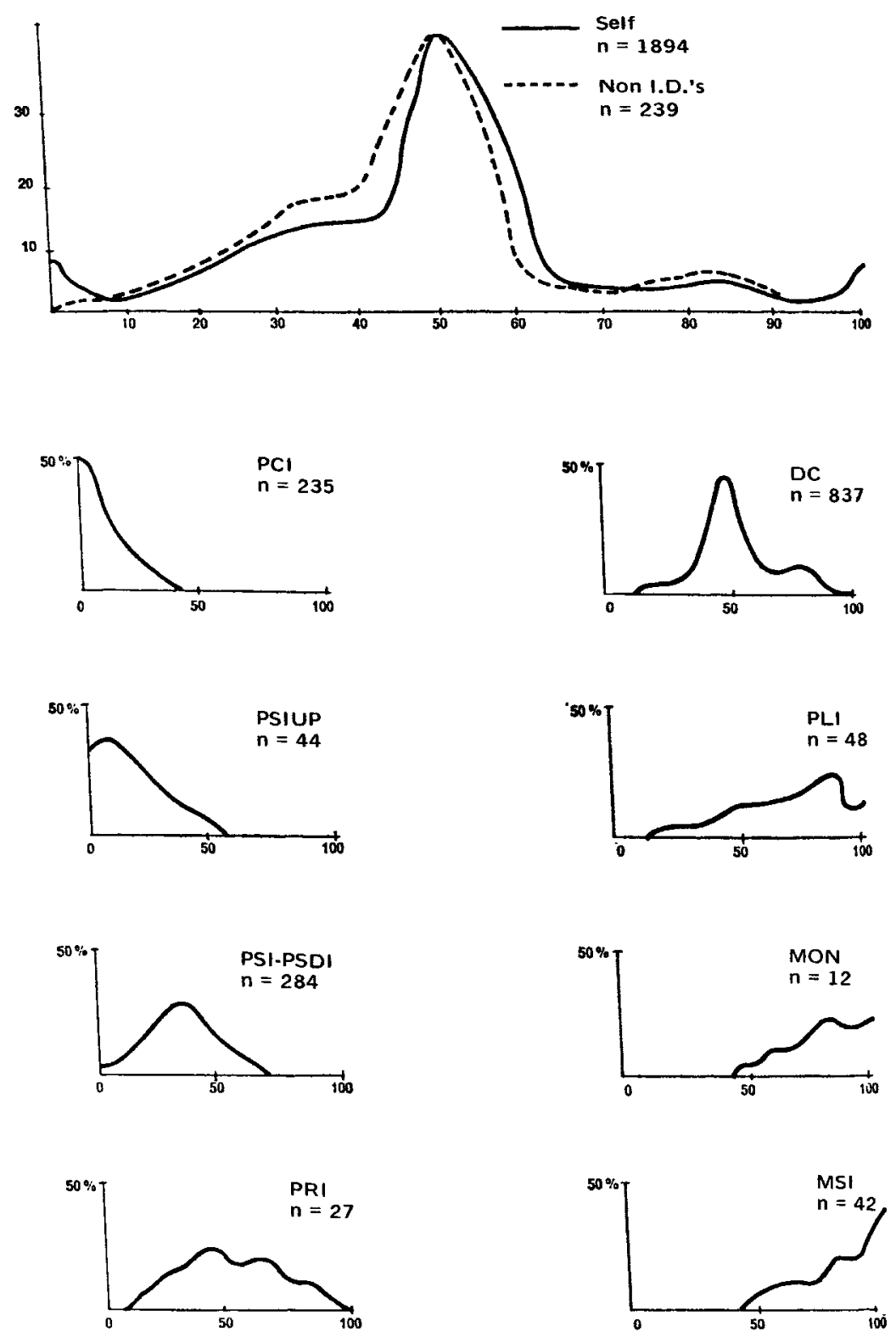

Figure 1: LEFT-RIGHT SELF-REPLACEMENT 
The most striking observation is the strong resemblance between the Christian Democratic distribution and that of the mass sample as a whole (see Figure 1). Of course, the sample somewhat overrepresents the DC and underrepresents the PCI and the right. Undoubtedly a better sample would reveal a somewhat stronger right and a considerably stronger extreme left, not to mention a less exaggerated center. However, it is unlikely that the general shape of the area under the curve would change greatly. The DC dominates the area in which the bulk of the electorate is to be found, which is not surprising considering that the party has ruled for a quarter-century.

It is also clear that the Italian electorate in 1968 was skewed to the left. The center-left formula thus certainly seems to reflect the distribution of opinion. The right, though well represented in parties, is weak in numbers. But its existence is a prerequisite for the center position of the DC. The Italian system does not appear to be highly polarized in left-right terms perhaps because the mass electorate's perception of the location of the three right-wing parties causes the $\mathrm{DC}$ to be viewed as a center party. If the composition of the space were to change, if the perspective were to be foreshortened by the elimination of the right, so to speak, then the DC might be viewed in quite different terms. Perhaps the same change could result from the emergence of a new force on the extreme left, one that would disrupt the current hold of the PCI on that position and push that party toward the center. But this is speculation. The historical memory of fascism, the existence of a Neofascist party and other clear Conservative parties, and perhaps other forces not yet isolated and analyzed placed the DC squarely in the center in 1968. In terms of the distribution of left-right perspectives at that time, the center-left formula seemed attuned to political realities.

\section{THE PROBLEM OF DIMENSIONS}

It is obvious that Italian politics does not revolve around a single, neatly ordered dimension. Many issues have historically been important in Italian politics and most of them are still current in debate. They surge and decline in importance, but few are resolved and fewer disappear. The existence of a number of parties is itself good evidence that there is more than one issue; for, though it is possible for several parties to exist based on advocacy of different magnitudes of a single issue, it is highly unlikely. Hence we must reconcile the existence of multiple issues with the single left-right dimension. 
An initial point that will simplify the problem is to point out that many issues responsible for the existence of minor parties seem to attract the attention of few voters. The parties of the left are anticlerical; the DC is proclerical; the right is much less clerical than the DC, but it attracts relatively few votes and hence attenuates only slightly the strong association between left and right and sympathy for the clergy. Similar dynamics hold for foreign policy, in which, for example, the MON and MSI are less pro-American than the parties to the immediate left of them. Thus it is possible for strong relationships to emerge even when the parties of the right revert toward the attitudes of the left on many variables. Taking the above phenomenon into account, it is remarkable the extent to which the left and the center, which are our two largest groups, represent opposite positions on most issues of public policy. A factor analysis of policy attitudes revealed that attitudes toward two socioeconomic issues, clericalism, and foreign policy form a single factor. On these dimensions (socioeconomic issues, clericalism, and foreign policy) the major blocs of left and center are at opposite poles. Hence the problem of conflicting dimensions is largely avoided by their coincidence, at least in this election. The placement of himself on a left-right scale seems not to confuse the respondent. Most seem to find little conflict among the dimensions.

That left-right placement is a better predictor of party identification than is any single issue or combination of issue dimensions is demonstrated by a stepwise multiple regression analysis. In order to meet better the assumptions of interval data the 0-100 self-placement of respondents on scales of sympathy toward clerics, unions, and Americans was used instead of the ordinal level responses to the policy questions. Left-right placement alone accounts for $42.8 \%$ of the total variance. Attitudes toward clerics adds an additional $5.7 \%$; attitudes toward unions explain an additional $2.9 \%$ beyond that; attitudes toward Americans adds a final $1.2 \%$ for a total variance explained of $52.6 \%$.

\section{ORDERED DIMENSIONS}

Ordered dimensions, it will be recalled, refers to the characteristic of a dimension that parties may be assigned different positions on it. "Position" issues can be so ranked while "valence" issues cannot. A large number of issues were investigated; we can place them into these two categories and look at their relationship to partisan identification.

Our procedure is to determine which are the issues that people say are important to them and then investigate which are the ones that in fact are 
highly associated with partisan identification. We will assume that the issues that are really the important ones in determining the respondent's identification are the ones that he associates with his party. Thus we asked whether certain things were important to the respondent and later asked which party struggled the most to achieve these things.

Three issues turned out to be important for everyone. These were the economic development of Italy, the development of education, and governmental stability. These are typical valence issues, things that are favored generally with most people seeing their own party as the one that struggles the most to achieve them. But when the strength of the relationship between party identification and perception of which party struggles the most for the issue is examined it is obvious that these are not the issues that distinguish among the parties. Table 3 demonstrates this. The position issues, on the other hand, show a diminishing relationship between ID and perception as the issue recedes in importance, as would be expected if the issue is an important one in party choice. That is, the relationship between ID and the perception that one's own party is the one that struggles most to achieve it is strongest for those for whom the issue is most important. It seems clear that the position issues are the ones that differentiate among the parties. One thus feels justified in acknowl-

TABLE 3

PARTISAN IDENTIFICATION AND `WHICH PARTY
STRUGGLES THE MOST TO . . . BY IMPORTANCE OF ISSUE

\begin{tabular}{|c|c|c|c|}
\hline & \multicolumn{3}{|c|}{ Valence Issues } \\
\hline & $\begin{array}{c}\text { Government } \\
\text { Stability }\end{array}$ & $\begin{array}{l}\text { Development } \\
\text { of Education }\end{array}$ & $\begin{array}{c}\text { Economic } \\
\text { Development }\end{array}$ \\
\hline Very important & $.70(917)$ & $.72(929)$ & .75 (1195) \\
\hline Somewhat important & .75 (285) & $.73(265)$ & $.85(167)$ \\
\hline Not very important & $.78(55)$ & $61(24)$ & .821 \\
\hline \multirow[t]{3}{*}{ Not at all important } & $.80(19)$ & $.80(4)$ & -1 \\
\hline & \multicolumn{3}{|c|}{ Position Issues } \\
\hline & Divorce & $\begin{array}{l}\text { Just Division } \\
\text { of Income }\end{array}$ & $\begin{array}{c}\text { Independence } \\
\text { of U.S. }\end{array}$ \\
\hline Very important & $.38(209)$ & $.64(821)$ & $.43(331)$ \\
\hline Somewhat important & $.22(198)$ & $.53(307)$ & $.28(181)$ \\
\hline Not very important & $.11(206)$ & $.18(65)$ & $.12(188)$ \\
\hline Not at all important & $-.06(527)$ & $.31(26)$ & $-.01(193)$ \\
\hline
\end{tabular}

(measure is tau beta; number of respondents is in parentheses) 
edging that valence issues exist in Italian politics while insisting that they are not very important in determining how people vote. They are ephemera, a halo that attaches to a party that is chosen on other grounds. We may conclude, consequently, that it is the ordered dimensions that count in Italian politics.

Additional evidence of the fit between ordered dimensions and party is found in the strong relationship between score on a policy index and party identification. The policy index was formed by taking the issue items identified in the factor analysis mentioned above and converting the sum of each respondent's answers into a single unweighted score. The index includes one clerical, one foreign policy, and two socioeconomic items. Respondents were asked whether they agreed strongly, agreed, disagreed, or disagreed strongly with the following statements: "We ought to stop financing Catholic schools and spend more money for state schools," "the foreign policy of Italy ought to be completely independent of the United States," "Capitalism poses a threat for Italy," and "in the division of the national income, workers are really in a disadvantageous position." The overall relationship is strong; tau beta is .40 and gamma is .55 . Table 4 shows the breakdown by party. The poor fit on the right is apparent, as are the large number of Christian Democrats without strongly voiced opinions.

Confidence in the overall results is increased when the strength of the relationship is examined for categories of respondents who have indicated varying degrees of closeness to their party. The closer their ties to the party the stronger the relationship, with party members exhibiting the strongest relationships of all (see Table 5).

TABLE 4

PARTY IDENTIFICATION AND POLICY POSITION Percentage of Each Party's Identifiers Taking Left-to-Right Positions

\begin{tabular}{lrrrrrrrrrr}
\hline $\begin{array}{l}\text { Policy } \\
\text { Position }\end{array}$ & PCI & PSIUP & $\begin{array}{c}\text { PSI- } \\
\text { PSDI }\end{array}$ & PRI & DC & PLI & MON & MSI & $\begin{array}{r}\text { No } \\
\text { ID }\end{array}$ & Total \\
\hline $\begin{array}{c}\text { Extreme } \\
\text { left 1 }\end{array}$ & 67 & 54 & 30 & 21 & 11 & 16 & 7 & 26 & 19 & 24 \\
$\begin{array}{c}\text { Modierate } \\
\text { left 2 }\end{array}$ & 20 & 32 & 32 & 52 & 23 & 14 & 43 & 21 & 27 & 26 \\
$\begin{array}{c}\text { Moderate } \\
\text { right 3 }\end{array}$ & 3 & 6 & 14 & 10 & 19 & 18 & 22 & 19 & 15 & 15 \\
$\begin{array}{c}\text { Extreme } \\
\text { right 4 }\end{array}$ & 1 & 2 & 9 & 10 & 19 & 47 & 14 & 28 & 11 & 14 \\
$\begin{array}{c}\text { No Response } \\
\quad 9\end{array}$ & 6 & 15 & 7 & 28 & 5 & 14 & 6 & 28 & 21 \\
Total \% & 100 & 100 & 100 & 100 & 100 & 100 & 100 & 100 & 100 & 100 \\
$n$ & 279 & 50 & 369 & 29 & 1048 & 56 & 14 & 47 & 517 & \\
\hline$n$
\end{tabular}




\section{TABLE 5}

\section{CLOSENESS TO PARTY AND RELATIONSHIP BETWEEN ID} AND POLICY POSITION ('Would you say that you feel very close to this party, more or less close, or not very close?")

\begin{tabular}{lccc}
\hline & Tau Beta & Gamma & n= \\
\hline Party members & .58 & .75 & 175 \\
Very close & .46 & .63 & 630 \\
More or less close & .39 & .54 & 755 \\
Not very close & .25 & .37 & 81 \\
DK, no answer & .28 & .41 & 39 \\
\hline
\end{tabular}

\section{COMMON ELITE-MASS REFERENCES}

The assumption of common elite-mass perceptions of political issues is the easiest of all to demonstrate for Italy-up to a point. The structure of political conflict ensures that only the most poorly informed are unaware of the positions of the politicians and parties on the major issues. But there are many poorly informed members of the electorate. ${ }^{2}$ There are also internal differences on some issues within some parties that affect the fit between issue position and party identification. Finally, the elite measures are based on members of only the three largest parties, and these are the ones that best fit the model.

The relationship between elite and mass perceptions can be summarized as follows: the elite are like the mass, only more so. The elite hold in an exaggerated form the opinions of the mass. Or perhaps the mass hold in attenuated form the opinions of the elite. For the relationship between opinion and party is much stronger for the elite than for the mass, and it is strikingly so in the dimensions that have been demonstrated to be extremely important for determining behavior, the clerical and socio economic areas. Unfortunately, as it was a communal elite being interviewed, we unwisely omitted the question dealing with foreign policy As we will demonstrate below by other means, the findings undoubtedly hold for this dimension as well.

Table 6 presents the overall relationships between opinion and party identification for the elite and for the mass. Stability is much mor strongly associated with party among the elite than the mass; otherwist the spread between elite and mass opinion is not remarkable, taking intc account the caveats uttered above. 
TABLE 6

RELATIONSHIP BETWEEN PARTY IDENTIFICATION AND VARIOUS

Top Line = Elite (PCI, PSI-PSDI, DC)

Middle Line $=$ Mass (PCI, PSI-PSDI, DC only)

Bottom Line in ( $)=$ Mass (all parties)

\begin{tabular}{|c|c|c|}
\hline & Tau Beta & Gamma \\
\hline Importance of government stability & $\begin{array}{l}-.42 \\
-.09 \\
(-.06)\end{array}$ & $\begin{array}{l}-.70 \\
-.17 \\
(-.10)\end{array}$ \\
\hline Importance of divorce law & $\begin{array}{r}.55 \\
.35 \\
(.25)\end{array}$ & $\begin{array}{c}.73 \\
.53 \\
(.35)\end{array}$ \\
\hline $\begin{array}{l}\text { Importance of equitable distribution of } \\
\text { national income }\end{array}$ & $\begin{array}{l}.19 \\
.19 \\
(.18)\end{array}$ & $\begin{array}{c}.50 \\
.37 \\
(.32)\end{array}$ \\
\hline Importance of economic development & $\begin{array}{c}.00 \\
.06 \\
(.06)\end{array}$ & $\begin{array}{c}.01 \\
.18 \\
(.16)\end{array}$ \\
\hline Agree workers disfavored & $\begin{array}{r}.54 \\
.24 \\
(.24)\end{array}$ & $\begin{array}{r}.80 \\
.42 \\
(.38)\end{array}$ \\
\hline Agree stop financing Catholic schools & $\begin{array}{c}.60 \\
.37 \\
(.31)\end{array}$ & $\begin{array}{c}.87 \\
.59 \\
\mid .45\}\end{array}$ \\
\hline Agree need divorce law & $\begin{array}{c}.69 \\
.39 \\
(.29)\end{array}$ & $\begin{array}{r}.91 \\
.58 \\
(.41)\end{array}$ \\
\hline Agree best possible education & $\begin{array}{c}-.14 \\
-.04 \\
(-.03)\end{array}$ & $\begin{array}{c}-.24 \\
-.08 \\
(-.04)\end{array}$ \\
\hline Agree Capitalism a threat & $\begin{array}{r}.59 \\
.34 \\
(.34)\end{array}$ & $\begin{array}{c}.81 \\
.51 \\
(.46)\end{array}$ \\
\hline Agree sad to see tradition go & $\begin{array}{c}.28 \\
.07 \\
(.08)\end{array}$ & $\begin{array}{r}.39 \\
.12 \\
(.13)\end{array}$ \\
\hline Agree unions too powerful & $\begin{array}{r}.28 \\
.18 \\
(.21)\end{array}$ & $\begin{array}{c}.41 \\
.27 \\
(.29)\end{array}$ \\
\hline
\end{tabular}


We also have a complete set of affect scores for the elite and mass (table not shown). These report the degree of sympathy for various groups and countries on a $0-100$ scale, with 50 representing neutral affect. The scores of elite and mass are close together, and in almost every case the mass scores regressed toward the national mean; that is, the mass opinions were less extreme than the elite. The exceptions are themselves of great interest, for they touch the sensitive issues of the system. These are the cases in which the opinions of a party's identifiers are further from the all-party mass mean than are elite opinions. There were 15 objects of sympathy and 3 parties, for a total of 45 cases. In all but 6 cases the mass regressed toward the mean; all 6 involved the Christian Democrats, and they all touched on aspects of the ideological debate that has served for so long as a vehicle of mass mobilization for the DC. The DC mass identifiers are more proclerical ( 73 to 61 ) than the elite, more pro-American (61 to 57), less sympathetic to the Russians (20 to 24), less sympathetic to the PSI-PSDI (46 to 52), less sympathetic to unions (60-64), and more sympathetic to big businessmen ( 47 to 43 ).

This indicates that DC elites work under considerable constraints in the opening to the left, and that they are in fact ahead of their electorate in moving toward the national mean. Note, however, that the spread between elite and mass is small; it is only the direction of the difference, not its magnitude, that merits attention. In most cases the spread between elite and mass is much greater for the PCI and PSI-PSDI, but in these parties the mass always regresses toward the national mean. It is in fact probably the extremism of the elites of the two leftist parties that accounts for the consistent regression of their mass identifiers toward the national mean. In the case of the DC, however, the errant choices of the mass cannot be explained away by the general phenomenon that extremes regress toward the mean on remeasurement or in larger populations. Though small, the differences in perception on general affect questions do seem to have important implications. But as we have seen they are not translated into differences between elite and mass in policy preferences.

\section{CONCLUSIONS}

From the foregoing it is clear that spatial models of politics correspond nicely with the reality world of the Italian electorate as it has been operationalized in this study. Unless one holds impossibly high standards 
as to what constitutes a good fit, the relationship between theory and data is very strong indeed.

This finding has implications for a wide range of considerations. Probably the most important is that it demonstrates that multiple dimensions of political conflict originating in diverse ages and circumstances need not be overlapping. For Italian political conflict reflects many issue dimensions that are not historically necessarily connected, though we have shown them to be in fact closely related. As new issues have arisen they tend to have been superimposed along the lines of old cleavages rather than crisscrossing them.

This is not to claim that cross-cutting cleavages do not exist. The difficulties between the center and right illustrate the dynamics of political conflict in Italy. The Liberals were traditionally an anticlerical party and they are still less clerical than the Christian Democrats. But because of the challenge of the left as well as other reasons this issue is played down today and the anticlerical aspect of liberalism has lost its political saliency. Another example is nationalism: the MSI is quite nationalist, but the importance of other conflicts in Italian politics keeps the party from being as anti-American as the leftist parties. In a similar way, issues originating in the counterreformation, the industrial revolution, and the cold war are transformed into poles of a single left-right scale.

If the issue dimensions of Italian politics were as clear-cut as suggested above there would be little reason for the multiparty system. Yet it is clear that voter opinions support such a system and, indeed, perhaps require it. For it is the large parties that fit the model best and it is the size of their electorates that makes the relationships so strong. Due to their size they are able in large part to define the issues and to impose their definitions on the electorate. And these are the issues that we have studied. There are many other issues in Italian politics that we have not tapped. It is not obvious that the lines of cleavage on these would be the same as those we have examined. Many have argued that the issues analyzed herein, which are certainly important in political debate, are irrelevant for the real issues of contemporary Italian society. And they may be correct. However, these old issues were still very much alive at the time of the research. Whether they will continue to be dominant in the minds of voters cannot be predicted with confidence. Their anchorage in the mass parties and the slow pace of change in Italian politics suggest that they may be around for quite a while. 


\section{NOTES}

1. The data are based on a multistage national sample of 3,000 , of whom 2,500 were interviewed, for a response rate of $83 \%$. The interviews were administered by CISER of Rome in June 1968.

2. This is perhaps the reason why the perceptions of the Monarchist identifiers fit so poorly with the conventional wisdom: they are the most uninformed and clientelistic of the party identifiers. It is likely that the conventional wisdom's placement of the party reflects accurately the attitudes of its elite. Unfortunately, we have no measures of MON elite attitudes to confirm or deny this hunch.

\section{REFERENCES}

CAMPBElL, A., P. E. CONVERSE, W. E. MILlER and D. E. STOKES (1966) "Spatial models of party competition" in Elections and the Political Order. New York: John Wiley.

DOWNS, A. (1957) An Economic Theory of Democracy. New York: Harper.

HOTELLING, H. (1929) "Stability in competition." Economic J. 39.

LAPONCE, I. A. (1970) "Note on the use of the left-right dimension." Comparative Pol. Studies 2 (January): 481-502.

SARTORI, G. (1965) "Modelli spaziali di competizione tra partiti." Rassegna italiana di sociologia 6 (January-March): 7-29.

SMITHIES, A. (1941) "Optimum location in spatial competition." J. of Pol. Economy 49. 